\title{
A comparative study of efficacy of argyreia speciosa and orlistat for their anti-obesity action in high fat diet induced obese rats
}

\author{
Suhas H. Patil*, Satkar Rajbhoj, Seema V. Bhalerao, Puja Jha, \\ Manasi V. Limaye, Mohanish U. Vaidya
}

Department of Pharmacology, Dr. D.Y. Patil Medical College, Hospital and Research Centre, Pimpri, Pune 411018, Maharashtra, India

Received: 12 January 2017 Accepted: 07 February 2017

*Correspondence to:

Dr. Suhas H. Patil,

Email:

drsuhashpatil@gmail.com

Copyright: (C) the author(s), publisher and licensee Medip Academy. This is an openaccess article distributed under the terms of the Creative Commons Attribution NonCommercial License, which permits unrestricted noncommercial use, distribution, and reproduction in any medium, provided the original work is properly cited.

\begin{abstract}
Background: To compare the anti-obesity action of Argyreia speciosa root extract with standard anti-obesity drug orlistat. Healthy Sprague-Dawley rats $(100-200 \mathrm{~g}, \mathrm{n}=50)$ were obtained from the animal house. Dose of Orlistat was $32.4 \mathrm{mg} / \mathrm{kg} /$ day and Dose of Argyreia speciosa root was $500 \mathrm{mg} / \mathrm{kg} /$ day.

Methods: Food induced obesity model was used. Following parameters were evaluated: Total Cholesterol (mg/dl), Triglyceride (mg/dl), HDL-cholesterol $(\mathrm{mg} / \mathrm{dl})$, LDL cholesterol $(\mathrm{mg} / \mathrm{dl})$, atherogenic index, serum lipase (U/L). Analysis was done by one way ANOVA followed by post-hoc test and Graph Pad Prism version 5.00 was used for the analysis.

Results: Total cholesterol, triglcerides, LDL cholesterol and Atherogenic index was significantly lesser in the rats fed with $\mathrm{CD}+\mathrm{O}$ group and $\mathrm{CD}+\mathrm{ASE}$ group than in the animals from $C D$ group $(p<0.05)$. It was also significantly lesser in the rats fed with $C D+O+A S E$ than in the animals from $C D$ group $(p<0.05)$. HDL cholesterol was significantly greater in the rats fed with $\mathrm{CD}+\mathrm{O}$ group and $\mathrm{CD}+\mathrm{ASE}$ group than in the animals from $\mathrm{CD}$ group $(\mathrm{p}<0.05)$. It was also significantly greater in the rats fed with $\mathrm{CD}+\mathrm{O}+\mathrm{ASE}$ than in the animals from CD group $(\mathrm{p}<0.05)$.

Conclusions: ASE significantly reduces total cholesterol $(\mathrm{mg} / \mathrm{dl})$, triglyceride $(\mathrm{mg} / \mathrm{dl})$, LDL cholesterol $(\mathrm{mg} / \mathrm{dl})$ and atherogenic index, it significantly increases HDL- cholesterol $(\mathrm{mg} / \mathrm{dl})$ and it is comparable to orlistat. Thus the anti-obesity action of ASE is comparable to orlistat.
\end{abstract}

Keywords: Anti-obesity, Argyreia speciosa, Cafeteria diet, Orlistat

\section{INTRODUCTION}

Obesity is a state of excess adipose tissue mass. Obesity has been considered an emerging health problem and in spite of the number of studies to prevent or treat obesity, its prevalence continues to rise. ${ }^{1}$

It may be defined by body mass index (BMI) and further evaluated in terms of fat distribution via the waist-hip ratio. BMI is closely related to both total body fat and percentage body fat. Morbid obesity is a more serious condition, which is correlated with a weight $170 \%$ greater than the ideal weight, or BMI greater than $40 \mathrm{~kg} / \mathrm{m}^{2}$.
The World Health Organization (WHO) predicts that obesity may soon replace traditional public health concerns such as under nutrition and infectious diseases as the most significant cause of poor health. Because of its costs, prevalence and health effects, obesity is a public health and policy problem. ${ }^{3}$

The barriers to the evaluation and treatment of obesity by health-care providers include a lack of awareness of obesity as an independent risk factor for morbidity and mortality and inadequate training in the medical management of obesity. However, the increased risk of medical disorders and emotional consequences associated with obesity make the disorder a priority for physicians to assess and treat. 
Orlistat is a lipase inhibitor for obesity management that acts by inhibiting the absorption of dietary fats. It is a potent, slowly reversible inhibitor of pancreatic and gastric lipases which are required for the hydrolysis of dietary fat into fatty acids. Taken at a therapeutic dose of $120 \mathrm{mg}$ tid, Orlistat blocks the digestion and absorption of about $30 \%$ of dietary fat in humans, thus making it popular for facilitating both weight loss and weight maintenance. ${ }^{1}$

Argyreia speciosa is one such plant which has recently been investigated for the antiobesity effects of its roots and Argyreia speciosa root extract has shown to inhibit the action of the pancreatic lipase enzyme in vitro in a dose dependent manner. ${ }^{4}$ The mechanism of action of Argyreia speciosa in vivo has not been investigated so far.

Hence, the present study was undertaken to compare antiobesity action of Argyreia speciosa root extract with standard antiobesity drug orlistat in food induced obesity models in rats.

\section{METHODS}

The commencement of the study was done after the approval from Institutional Animal Ethics Committee (IAEC).

The experiments were performed as per norms laid by Committee for the Purpose of Control and Supervision of Experimentation on Animals (CPCSEA).

\section{Animals used in this study}

Healthy Sprague-Dawley rats $(100-200 g, n=50)$ were obtained from the animal house of Dr. D. Y. Patil Medical College, Pimpri, Pune. Animals were housed in quarantine room individually in metabolic cages. Standard laboratory conditions were maintained with 12:12 hour light: dark cycle with a room temperature of $28 \pm 4^{\circ} \mathrm{C}$.

\section{Drugs used in the study}

\section{Orlistat}

The suspension was prepared by Rasashastra and Bhaishyajya Kalpana Department, Dr. D. Y. Patil College of Ayurved and Research Centre Pimpri, Pune.

Dose $=32.4 \mathrm{mg} / \mathrm{kg} / \mathrm{day}^{5}$

\section{Argyreia speciosa root}

Roots were obtained from Manakarnika Aushadhalaya, Pune and verified by the Department of Botany, University of Pune. The roots were air dried, powdered, and then extracted with $70 \%$ ethanol by using the soxhlet method. The extract was filtered with Whatman No. 1 filter paper and then the solvent evaporated at a reduced pressure by using the Rotavapor apparatus to get a viscous mass, which was then stored at $4^{0} \mathrm{C}$ until used. Ethanolic extract was prepared by Rasashastra and Bhaishyajya Kalpana Department, Dr. D. Y. Patil College of Ayurved \& Research Centre Pimpri, Pune-18 and used as a suspension in Tween 80 .

The dose was determined by previously conducted toxicity studies. ${ }^{2}$

Dose $=500 \mathrm{mg} / \mathrm{kg} / \mathrm{day}$

\section{Normal diet}

The regular laboratory chows were is used.

\section{High fat diet/Cafeteria diet (CD)}

The CD consisted of three diets: ${ }^{4}$

a) Condensed Milk (8g) + Bread (8g)

b) Chocolate $(3 \mathrm{~g})+$ Biscuits $(6 \mathrm{~g})+$ Dried Coconut (6g)

c) Cheese $(8 g)+$ Boiled Potato $(10 g)$

The three diets were presented to the individual rats on days one, two, and three, respectively, and then repeated for 12 weeks in the same succession Composition and calorie value of the cafeteria diet is given in Table 1 .

Table 1: Composition and calorie value of the cafeteria diet.

\begin{tabular}{|ll|}
\hline Ingredients & Calorie value (kcal/100g) \\
\hline Condensed milk & 335 \\
\hline Bread & 230 \\
\hline Chocolate & 550 \\
\hline Biscuit & 360 \\
\hline Dried coconut & 660 \\
\hline Cheese & 320 \\
\hline Boiled potato & 80 \\
\hline
\end{tabular}

\section{Grouping}

Animals were divided into 5 groups $(\mathrm{n}=10)$ as given in Table 2.

\section{Food induced obesity model}

Animals were used after 1 week of adaptation period in a temperature and humidity controlled room with a 12:12 hour light and dark cycle.

The animals were fed diet as per their groups ad libitum with free access to water. The study period is of three months and parameters were measured at the beginning, during and at the end of the experiment. 
Table 2: Grouping of animals used in the study.

\begin{tabular}{|lll|}
\hline Group & Type & Diet \\
\hline C & Control group & $\begin{array}{l}\text { Normal diet } \\
\text { (laboratory } \\
\text { pellet chows) }\end{array}$ \\
\hline CD & $\begin{array}{l}\text { Cafeteria Diet (CD) } \\
\text { group }\end{array}$ & CD \\
\hline CD+O & $\begin{array}{l}\text { Cafeteria Diet (CD) }+ \\
\text { Orlistat (O) treated } \\
\text { group }\end{array}$ & CD + O \\
& $\begin{array}{l}\text { Cafeteria Diet (CD) }+ \\
\text { Argyreia speciosa } \\
\text { extract(ASE) treated } \\
\text { group }\end{array}$ & CD + ASE \\
\hline CD+O+ASE & $\begin{array}{l}\text { Cafeteria Diet (CD) }+ \\
\text { Orlistat (O) + Argyreia } \\
\text { speciosa extract (ASE) } \\
\text { treated group }\end{array}$ & CD + O + \\
\hline
\end{tabular}

\section{Parameters}

Blood biochemical analysis

At the beginning and end of the study, blood was collected by retro-orbital puncture for the following blood biochemical analysis:

(a) Lipid profile

- Total cholesterol (TC)

- Triglyceride (TG)
- High density lipoprotein (HDL)

- Low density lipoprotein (LDL)

Atherogenic Index was calculated by:

\section{$\underline{\text { Total cholesterol - HDL7 }}$} HDL

(b) Serum lipase levels (U/L)

The analysis was done by Central Clinical Laboratory of Dr. D.Y. Patil Medical College \& Hospital, Pimpri, Pune 18.

Plan for data analysis:

- The analysis of the results was done by one way ANOVA followed by post-hoc test.

- Graph Pad Prism version 5.00 was used for the analysis.

\section{RESULTS}

\section{Blood biochemical analysis}

At 12 weeks: TC was significantly lesser in the rats fed with in the $\mathrm{CD}+\mathrm{O}$ group [95\% CI 56.55 to 67.45 $(\mathrm{p}<0.05)$ ] and CD+ASE group [95\% CI 50.1 to 59.5 $(\mathrm{p}<0.05)]$ than in the animals from CD group. It was also significantly lesser in the rats fed with $\mathrm{CD}+\mathrm{O}+\mathrm{ASE}$ than in the animals from CD group [95\% CI 62.08 to 72.52 $(\mathrm{p}<0.05)]$ and CD+ASE group [95\% CI 6.88 to 18.12 $(\mathrm{p}<0.05)]$.

Table 3: Comparison of anthropometrical parameters between different groups (Mean \pm SEM).

\begin{tabular}{|c|c|c|c|c|c|c|}
\hline \multirow{2}{*}{ Parameter } & \multirow{2}{*}{ No. of weeks } & \multicolumn{5}{|l|}{ Groups } \\
\hline & & $\mathbf{C}$ & CD & $\mathrm{CD}+\mathrm{O}$ & CD+ASE & $\mathrm{CD}+\mathrm{O}+\mathrm{ASE}$ \\
\hline \multirow{2}{*}{ Total Cholesterol (mg/dl) } & 0 & $94.27 \pm 1.2$ & $95.2 \pm 2.31$ & $94.3 \pm 2.09$ & $93.8 \pm 3.04$ & $94.73 \pm 2.67$ \\
\hline & 12 & $98.6 \pm 1.78$ & $138.7 \pm 1.42$ & $76.7 \pm 2.17$ & $83.9 \pm 1.73$ & $71.4 \pm 2.04$ \\
\hline \multirow{2}{*}{ Triglyceride (mg/dl) } & 0 & $76.25 \pm 3.26$ & $78.75 \pm 2.36$ & $75.96 \pm 1.64$ & $78.34 \pm 1.23$ & $77.25 \pm 1.27$ \\
\hline & 12 & $80.35 \pm 2.16$ & $110.98 \pm 2.37$ & $54.84 \pm 2.12$ & $60.67 \pm 1.13$ & $50.56 \pm 1.06$ \\
\hline \multirow{2}{*}{ HDL-Cholesterol (mg/dl) } & 0 & $23.6 \pm 1.08$ & $24.4 \pm 1.18$ & $23.5 \pm 1.17$ & $23.8 \pm 1.2$ & $23.4 \pm 1.36$ \\
\hline & 12 & $27.16 \pm 0.22$ & $27.3 \pm 0.95$ & $34.9 \pm 1.59$ & $32 \pm 1$ & $34 \pm 0.84$ \\
\hline \multirow{2}{*}{ LDL-Cholesterol (mg/dl) } & 0 & $50.18 \pm 1.73$ & $48.29 \pm 1.71$ & $49.52 \pm 2.70$ & $46.03 \pm 1.73$ & $45.83 \pm 1.74$ \\
\hline & 12 & $60.19 \pm 1.02$ & $128.19 \pm 2.01$ & $45.19 \pm 1.09$ & $52.85 \pm 1.82$ & $40.02 \pm 1.20$ \\
\hline \multirow{2}{*}{ Atherogenic Index } & 0 & $3.08 \pm 0.22$ & $3 \pm 0.25$ & $3.12 \pm 0.25$ & $3.04 \pm 0.25$ & $3.20 \pm 0.31$ \\
\hline & 12 & $2.63 \pm 0.05$ & $4.13 \pm 0.18$ & $1.25 \pm 0.14$ & $1.67 \pm 0.08$ & $1.11 \pm 0.08$ \\
\hline \multirow{2}{*}{ Serum lipase (U/L) } & 0 & $16.85 \pm 0.2$ & $17.28 \pm 0.16$ & $16.98 \pm 0.28$ & $17.15 \pm 0.16$ & $16.99 \pm 0.15$ \\
\hline & 12 & $17.01 \pm 0.19$ & $17.58 \pm 0.14$ & $17.35 \pm 0.11$ & $16.85 \pm 0.19$ & $16.12 \pm 0.14$ \\
\hline
\end{tabular}

At 12 weeks: TG was significantly lesser in the rats fed with CD+O group [95\% CI 49.46 to $62.82(\mathrm{p}<0.05)]$ and CD+ASE group [95\% CI 44.79 to 55.83 ( $\mathrm{p}<0.05)$ ] than in the animals from CD group. TG was significantly lesser in the rats fed with $\mathrm{CD}+\mathrm{O}+\mathrm{ASE}$ group than in the animals from CD group [95\% CI 54.97 to 65.87 $(\mathrm{p}<0.05)]$ and CD+ASE group [95\% CI 6.855 to 13.37 $(\mathrm{p}<0.05)]$. At 12 weeks: HDL was significantly greater in 
the rats fed with $\mathrm{CD}+\mathrm{O}$ group [95\% CI -11.49 to -3.709 $(\mathrm{p}<0.05)]$ and CD+ASE group $[95 \%$ CI-7.59 to$1.802(\mathrm{p}<0.05)]$ than in the animals from CD group. HDL was significantly greater in the rats fed with CD+O+ASE than in the animals from CD group [95\% CI -9.364 to $4.036(\mathrm{p}<0.05)]$.

At 12 weeks: LDL was significantly lesser in the rats fed with CD+O group [95\% CI 78.2 to $87.8(\mathrm{p}<0.05)$ ] and CD+ASE group [95\% CI 69.64 to $81.04(p<0.05)$ ] than in the animals from CD group. LDL was significantly lesser in the rats fed with $\mathrm{CD}+\mathrm{O}+\mathrm{ASE}$ group than in the animals from CD group [95\% CI 83.25 to 93.09 $(\mathrm{p}<0.05)]$ and CD+ASE group [95\% CI 8.25 to 17.41 $(\mathrm{p}<0.05)]$.

At 12 weeks: AI was significantly lesser in the rats fed with CD+O group [95\% CI 2.401 to $3.359(\mathrm{p}<0.05)$ ] and CD+ASE group [95\% CI 2.046 to $2.874(\mathrm{p}<0.05)$ ] than in the animals from $\mathrm{CD}$ group. AI was significantly lesser in the rats fed with $\mathrm{CD}+\mathrm{O}+\mathrm{ASE}$ than in the animals from CD group [95\% CI 2.606 to $3.434 \quad(\mathrm{p}<0.05)]$ and $\mathrm{CD}+\mathrm{ASE}$ group [95\% CI 0.3223 to $0.7977(\mathrm{p}<0.05)$ ].

\section{DISCUSSION}

Obesity is still widely described as a lifestyle 'choice', but even determined changes in lifestyle may have limited long-term impact on it and, pragmatically, the need for medical intervention is now clear. Surgical or endoscopic bariatric procedures are effective therapies for obesity, but bariatric surgery in particular carries significant peri-operative morbidity and mortality. Moreover, it is very expensive, recommended for severe obesity and thus restricted in many healthcare systems. Therefore, there is clearly an important role for pharmacotherapy as an adjunct to lifestyle changes. ${ }^{6}$

Current pharmacological intervention in obesity is limited by the availability of a few licensed drugs. Available drugs have limited efficiency and many untoward effects. Orlistat is the sole medication licensed for the treatment of obesity in UK. NICE (National Institute for Health and Care Excellence) guidelines limit its use for 2 years. ${ }^{7}$

In this study, it is observed that there is significant increase in serum lipids, such as Total Cholesterol (TC), Low Density Lipoprotein (LDL), and Triglycerides (TG) in obese animals. Further, there is a decrease in HDL/ LDL ratio. Thus, alteration of lipid profiles can be used as an index of obesity. Treatment with ASE resulted in significant changes in the blood parameters, including decreased levels of $\mathrm{TC}$, LDL, and TG, but increased HDL.

Argyreia speciosa is one such plant which has recently been investigated for the antiobesity effects of its roots and Argyreia speciosa root extract (ASE) has shown to inhibit the action of the pancreatic lipase enzyme in vitro in a dose dependent manner. ${ }^{4}$ The mechanism of action of
Argyreia speciosa in vivo has never been investigated before.

\section{CONCLUSION}

In the present study, antiobesity action of Argyreia speciosa root extract (ASE) is evaluated and compared with the standard antiobesity drug, orlistat. From this study following conclusions can be made:

1. ASE has a positive effect on serum lipid profile i.e. decrease in total cholesterol, triglycerides, LDL and increase in HDL and it is comparable to orlistat.

2. No significant change in serum lipase levels seen in any group. This may be due to less systemic absorption of ASE and orlistat.

The antiobesity action of ASE is comparable to orlistat. ASE produces positive changes in lipid profile. These results provide the rational basis for ASE use in traditional medicine for the treatment of obesity as treatment with ASE resulted in significant changes in the blood parameters, including decreased levels of TC, LDL, and TG, but increased HDL.

We measured the serum lipase levels at the beginning and end of the study in a bid to find the effect of ASE on pancreatic lipase in vivo. There was no significant difference in these levels between any of the groups in the study. This finding was also observed in orlistat treated group which is known to have no significant action on serum lipase levels. This can be explained by no systemic absorption of orlistat. ASE, on similar lines of orlistat, might be having no systemic absorption.

Further, studies are required to isolate and characterize the phytoconstituents responsible for the antiobesity activity of ASE and explore its mechanism of action more precisely.

\section{Funding: No funding sources}

Conflict of interest: None declared

Ethical approval: The study was approved by the Institutional Ethics Committee

\section{REFERENCES}

1. Fausi AS, Kasper DL. Harrison's Principles of Internal Medicine. $18^{\text {th }}$ ed. New York: McGraw-Hill Medical publishing division; 2010:622-635.

2. The National Institutes of Health (NIH) Consensus Development Program: Gastrointestinal Surgery for Severe Obesity; 1991. Available from: http://consensus.nih.gov/1991/1991 gisurgeryobesity0 84html.htm

3. WHO. Obesity and overweight. World Health Organization; 2014. Available from: http://www.who.int/mediacentre/factsheets/fs311/en/

4. Kumar S, Alagawadi KR, Rao MR. Effect of Argyreia speciosa root extract on cafeteria diet- 
induced obesity in rats. Indian $\mathrm{J}$ Pharmacol. 2011;43:163-7.

5. Ghosh MN. Fundamentals of experimental pharmacology. $3^{\text {rd }}$ ed. Kolkata: Hilton and company;2005

6. Bharatha A. Evaluation of Caralluma fimbriata extract in animal models of obesity. Dr. D. Y. Patil Vidyapeeth (Deemed University), Pune; 2015.
7. Carter R, Mouralidarane A, Ray S, Soeda J, Oben J. Recent advancements in drug treatment of obesity. Clinical Medicine. 2012;12(5):456-60.

Cite this article as: Patil SH, Rajbhoj S, Bhalerao SV, Jha P, Limaye MV, Vaidya MU. A comparative study of efficacy of argyreia speciosa and orlistat for their anti-obesity action in high fat diet induced obese rats. Int J Basic Clin Pharmacol 2017;6:613-7. 